\title{
Iron(III) and copper(II) complexes of trans-bis(ferrocenyl)porphyrin: Effect of metal ions on long-range electronic communication
}

\author{
DIPANKAR SAHOO and SANKAR PRASAD RATH* \\ Department of Chemistry, Indian Institute of Technology Kanpur, Kanpur 208 016, India \\ e-mail: sprath@iitk.ac.in
}

MS received 12 December 2013; accepted 29 January 2015

\begin{abstract}
A series of complex with a general formula of $\mathrm{M}\left(\mathrm{Fc}_{2} \mathrm{Ph}{ }_{2} \mathrm{P}\right)\left[\mathrm{Fc}_{2} \mathrm{Ph}_{2} \mathrm{P}=5,10\right.$-bisferrocenyl-15,20bisphenylporphyrin (2-); $\mathrm{M}=\mathrm{Fe}(\mathrm{III}) \mathrm{Cl} \mathrm{Fe}(\mathrm{III})\left(\mathrm{ClO}_{4}\right)$ and $\left.\mathrm{Cu}(\mathrm{II})\right]$ have been synthesized and characterized. The single crystal X-ray structure of $\mathrm{Cu}^{\mathrm{II}}\left(\mathrm{Fc}_{2} \mathrm{Ph}_{2} \mathrm{P}\right)$ has been reported in which two ferrocene moieties are in anti form with respect to each other. The ferrocenyl groups of $\mathrm{Cu}^{\mathrm{II}}\left(\mathrm{Fc}_{2} \mathrm{Ph}_{2} \mathrm{P}\right)$ are more easily oxidized via a single two-electron quasi-reversible process compared to the free base ligand in which two 1e-oxidative response separated by $0.23 \mathrm{~V}$ are observed. Electrochemical study of $\mathrm{Fe}^{\mathrm{III}}\left(\mathrm{Fc}_{2} \mathrm{Ph}_{2} \mathrm{P}\right) \mathrm{Cl}$ revealed ferrocenebased two-electron quasi-reversible oxidation at $0.72 \mathrm{~V}$ indicating no observable coupling of the ferrocene moieties. The higher oxidation state of Fe(III) reduces the electron releasing tendency of the porphyrin ring and thus make the ferrocene oxidation difficult. The porphyrin, however, lack substituents at the $\beta$-pyrrolic positions, and the ferrocenyl moieties are therefore free to rotate. The observed electrochemical analyses thus demonstrate that the oxidation of the ferrocene subunit is strongly affected by porphyrin ring as well as the central metal through extended $\pi$-conjugation.
\end{abstract}

Keywords. Ferrocenylporphyrin; electrochemistry; spectro-electrochemistry; electrochemical conjugation; $\mathrm{X}$-ray structure determination.

\section{Introduction}

The multiple redox active centers are of fundamental importance for the development of molecular-based electronic devices or molecular electrogenic sensors. ${ }^{1}$ Ferrocene-porphyrin conjugates have great potential in such areas due to their donor-acceptor complementary and electrochemical activities. Their ability to reversibly accept and/or release several electrons at distinct potentials is particularly interesting in multielectron redox catalysis and can be used for multibit information storage at the molecular level. ${ }^{1-4}$ The peripheral substitution around the porphyrin ring along with the nature of the organic linkage between these redox active centers have been shown to drastically influence their 'communication' and numerous studies are aimed at characterizing and understanding these interactions.

A large variety of ferrocene-appended porphyrins or porphyrin analogues have been reported in the literature. ${ }^{4}$ The outstanding thermal and chemical stability as well as the possibility of tuning the macrocyclic redox potentials make porphyrins and related compounds outstanding candidates as $\pi$-conjugated

\footnotetext{
*For correspondence
}

skeletons, which are able to connect several redoxactive ferrocenyl substituents at various available positions ${ }^{5}$ Ferrocene linked by olefin bridges show larger metal-metal interactions than those linked by analogues of saturated carbon. Two redox active ferrocene units linked by $\pi$-conjugation can be expected to show intramolecular and intermolecular interactions, so-called electrochemical communication, of the ferrocenyl groups. When one of the two ferrocenyl groups is oxidized to the monocation, the delocalization of the cationic charge between ferrocene and ferrocenium ion may occur to give a mixed valence state. ${ }^{6,7}$ Recent studies identify at least some of the factors that influence electrochemical interaction between connected ferrocene moieties, including the nature, type and length of the connector and the orientation of the two ferrocene moieties. Examples of strong, long-range (>10 ̊) metal-metal coupling are already reported for the metal-free and nickel and manganese complexes of $\alpha, \alpha-5,15$-bis(ferrocenyl)-2,8,12,18-tetrabutyl-3,7, 13,17 -tetramethylporphyrins. ${ }^{5}$ In these cases, pure atropisomers of the metal-free and transition-metal $\alpha$, $\alpha$-5,15-bis(ferrocenyl)-2,3,7,8,12,13,17,18-octaalkylporphyrins demonstrated long-range metal-metal coupling between two ferrocenyl substituents. In the present work, we report the synthesis, structure and 
properties of $\mathrm{Fe}(\mathrm{III})$ and $\mathrm{Cu}(\mathrm{II})$ complexes of trans diferrocenylporphyrin in which the ferrocenyl groups are free to rotate due to lack of substituent at the $\beta$-pyrrolic positions. The effects of central metal ions have been explored in details.

\section{Experimental}

\subsection{Materials}

5,15-bisferrocenyl-10,20-bisphenylporphyrin (trans $-\mathrm{H}_{2}$ $\mathrm{Fc}_{2} \mathrm{Ph}_{2} \mathrm{P}$ ) was prepared by literature methods. ${ }^{6 \mathrm{a}}$ GradeIII basic alumina was used for column chromatography. Reagents and solvents are purchased from the commercial sources and purified by standard procedures before use.

2.1a $\mathrm{Fe}^{I I I}\left(\mathrm{Fc}_{2} \mathrm{Ph} \mathrm{h}_{2} \mathrm{P}\right) \mathrm{Cl}: \quad 100 \mathrm{mg}$ of $\mathrm{H}_{2} \mathrm{Fc}_{2} \mathrm{Ph}_{2} \mathrm{P}(0.12$ $\mathrm{mmol}$ ) was dissolved in $100 \mathrm{~mL}$ dimethylformamide; excess $\mathrm{FeCl}_{2}$ was added and the mixture was refluxed for $2.5 \mathrm{~h}$ under nitrogen atmosphere. The resulting solution was then cooled and transferred to a separatory funnel. $100 \mathrm{~mL}$ dichloromethane was added to the mixture which was then washed with $0.2(\mathrm{~N}) \mathrm{HCl}(3 \times 200$ $\mathrm{mL})$. Organic layer was separated and dried over anhydrous $\mathrm{Na}_{2} \mathrm{SO}_{4}$. The resulting solution was evaporated to complete dryness and purified by column chromatography using silica gel. The major fraction, eluted with chloroform, was collected and vacuum dried to obtain brown solid. Yield: $80 \mathrm{mg}$ (72\%). Anal. Calcd (found): C, 67.88 (67.97); H, 3.95 (4.10); N, 6.09 (6.18). UVvis(dichloromethane) $\left[\lambda_{\max }, \mathrm{nm}\left(\varepsilon, \mathrm{M}^{-1} \mathrm{~cm}^{-1}\right)\right]: 420$ $\left(7.5 \times 10^{4}\right), 486\left(4.5 \times 10^{2}\right), 632\left(9.9 \times 10^{1}\right) .{ }^{1} \mathrm{H}$ NMR $\left(\mathrm{CDCl}_{3}, 295 \mathrm{~K}\right): \beta-H: 78 ; \alpha-\mathrm{Cp}: 13.24 ; \beta-\mathrm{Cp}: 12.27$; $\mathrm{Cp}-\mathrm{H}: 9.16$ ppm. EPR data: in dichloromethane (120 $\mathrm{K}), \mathrm{g}_{\perp}=5.96$ and $\mathrm{g}_{\mathrm{II}}=1.99 . \mathrm{E}_{1 / 2}, \mathrm{~V}(\Delta \mathrm{Ep}, \mathrm{mV}): 0.72$ (70).

2.1b $\mathrm{Fe}^{I I I}\left(\mathrm{Fc}_{2} \mathrm{Ph}_{2} \mathrm{P}\right) \mathrm{ClO}_{4}: 100 \mathrm{mg}$ of $\mathrm{Fe} \mathrm{III}^{\mathrm{II}}\left(\mathrm{Fc}_{2} \mathrm{Ph}_{2} \mathrm{P}\right) \mathrm{Cl}$ $(0.109 \mathrm{mmol})$ was dissolved in $100 \mathrm{~mL}$ benzene. A saturated acetonitrile solution of $\mathrm{AgClO}_{4}(24 \mathrm{mg}, 0.12$ mmol) was added to the resulting solution which was then stirred for an hour under nitrogen atmosphere. After the removal of $\mathrm{AgCl}$ by filtration, heptane (10 $\mathrm{mL}$ ) was added, and the solution was then allowed to stand overnight. The purple crystalline products were collected by filtration, washed with hexane, and dried in vacuum at room temperature to give the compound. Yield: $70 \mathrm{mg}(65 \%)$. Anal. Calcd (found): C, 63.46 (63.53); H, 3.69 (3.74); N, 5.70 (5.63). UV-vis (dichloromethane) $\left[\lambda_{\max }, \mathrm{nm}\left(\varepsilon, \mathrm{M}^{-1} \mathrm{~cm}^{-1}\right)\right]: 397$ (7.3 x $\left.10^{3}\right), 619\left(6.5 \times 10^{1}\right),{ }^{1} \mathrm{H}$ NMR $\left(\mathrm{CDCl}_{3}, 295 \mathrm{~K}\right)$ :
$\beta-H: 36 ; \alpha$-Cp: 13.24; $\beta$-Cp: 12.27; Cp-H: 9.16 ppm. EPR data: in dichloromethane $(120 \mathrm{~K}): \mathrm{g}_{\perp}=5.64$ and $\mathrm{g}_{\mathrm{II}}=2.00$.

2.1c $C u^{I I}\left(F c_{2} P h_{2} P\right)$ : A solution of $\mathrm{Cu}(\mathrm{OAc})_{2}(87 \mathrm{mg}$, $0.48 \mathrm{mmol})$ in methanol $(20 \mathrm{~mL})$ was added to a chloroform solution (100 mL) of $\mathrm{H}_{2} \mathrm{Fc}_{2} \mathrm{Ph}_{2} \mathrm{P}$ under nitrogen. The mixture was then refluxed for $2 \mathrm{~h}$, cooled to room temperature and was dried in vacuum. The solid residue was then purified by column chromatography on silica gel. The major fraction, eluted with chloroform, was collected and vacuum dried to obtain brown solid of the complex. Yield: $78 \mathrm{mg}$ (73\%). Anal. Calcd (found): C, 69.99 (70.01); H, 4.07 (4.12); N, 6.28 (6.24). UVvis (dichloromethane) $\left[\lambda_{\max }, \mathrm{nm}\left(\varepsilon, \mathrm{M}^{-1} \mathrm{~cm}^{-1}\right)\right]: 415$ $\left(5.8 \times 10^{4}\right), 550\left(7.2 \times 10^{1}\right), 625\left(6.3 \times 10^{1}\right)$. EPR data: in dichloromethane $(120 \mathrm{~K}), \mathrm{g}_{\perp}=2.06$ and $\mathrm{g}_{\mathrm{II}}=2.21$. $\mathrm{E}_{1 / 2}, \mathrm{~V}(\Delta \mathrm{Ep}, \mathrm{mV})$ : 0.44(75); 1.0(65); 1.3(60).

\subsection{Instrumentation}

UV-vis spectra were recorded on a PerkinElmer UV/vis spectrometer. Elemental $(\mathrm{C}, \mathrm{H}$ and $\mathrm{N})$ analyses were performed on a Perkin-Elmer 2400II elemental analyzer. ${ }^{1} \mathrm{H}$ NMR spectra were recorded on a JEOL $500 \mathrm{MHz}$ instrument. The spectra for paramagnetic molecules were recorded over a $100 \mathrm{kHz}$ bandwidth with $64 \mathrm{~K}$ data points and a $5 \mu \mathrm{s} 90^{\circ}$ pulse. For a typical spectrum, between 2000 and 3000 transients were accumulated with a $50 \mathrm{~ms}$ delay time. The residual ${ }^{1} \mathrm{H}$ resonances of the solvents were used as a secondary reference. Electron paramagnetic resonance (EPR) spectra were obtained on a Bruker EMX EPR spectrometer. Cyclic voltammetric studies were performed on a BAS Epsilon electrochemical workstation in dichloromethane with $0.1 \mathrm{M}$ tetrabutylammonium hexa-fluorophoshate (TBAH) as supporting electrolyte and the reference electrode was $\mathrm{Ag} / \mathrm{AgCl}$ and the auxiliary electrode was a $\mathrm{Pt}$ wire. The concentration of the compounds was in the order of $10^{-3} \mathrm{M}$. The ferrocene/ferrocenium couple occurs at $\mathrm{E}_{1 / 2}=+0.45$ (65) $\mathrm{V}$ versus $\mathrm{Ag} / \mathrm{AgCl}$ under the same experimental conditions.

\section{$2.3 X$-ray structure solution and refinement}

A suitable crystal of $\mathrm{Cu}^{\mathrm{II}}\left(\mathrm{Fc}_{2} \mathrm{Ph}_{2} \mathrm{P}\right)$ was coated with light hydrocarbon oil and mounted in the $100 \mathrm{~K}$ dinitrogen stream of Bruker SMART APEX CCD diffractometer equipped with CRYO industries low-temperature apparatus. Intensity data were collected using graphitemonochromated Mo $\mathrm{K} \alpha$ radiation $(\lambda=0.71073 \AA)$ while SAINT software ${ }^{8}$ was used for data integration 
Table 1. Crystaldata and data collection parameters of $\mathrm{Cu}^{\mathrm{II}}\left(\mathrm{Fc}_{2} \mathrm{Ph}_{2} \mathrm{P}\right)$.

\begin{tabular}{|c|c|}
\hline $\mathrm{T}, \mathrm{K}$ & $100(2)$ \\
\hline Formula & $\mathrm{C}_{52} \mathrm{H}_{36} \mathrm{CuFe} \mathrm{Fe}_{2} \mathrm{~N}_{4}$ \\
\hline Crystal size $\left(\mathrm{mm}^{3}\right)$ & $0.26 \times 0.22 \times 0.18$ \\
\hline Formula weight & 892.09 \\
\hline Crystal system & Monoclinic \\
\hline Color & Dark red \\
\hline Space group & $P 2_{1} / \mathrm{c}$ \\
\hline$a, \AA$ & $9.659(4)$ \\
\hline$b, \AA$ & $10.614(5)$ \\
\hline$c, \AA$ & $18.021(8)$ \\
\hline$\alpha, \operatorname{deg}$ & 90 \\
\hline$\beta, \operatorname{deg}$ & $98.445(10)$ \\
\hline$\gamma$, deg & 90 \\
\hline$V, \AA^{3}$ & $1827.7(14)$ \\
\hline $\operatorname{Radiation}(\lambda, \AA)$ & Mo K $\alpha(0.71073)$ \\
\hline$Z$ & 2 \\
\hline$d_{\text {calcd }}, \mathrm{g} \bullet \mathrm{cm}^{-3}$ & 1.621 \\
\hline$\mu, \mathrm{mm}^{-1}$ & 1.407 \\
\hline$F(000)$ & 914 \\
\hline No of unique data & 3381 \\
\hline No. of parameters refined & 268 \\
\hline GOF on $F^{2}$ & 1.016 \\
\hline$R 1^{\mathrm{a}[I>2 \sigma(I)]}$ & 0.0534 \\
\hline$R 1^{\mathrm{a}}$ (all data) & 0.0737 \\
\hline $\mathrm{w} R 2^{\mathrm{b}}$ (all data) & 0.1405 \\
\hline
\end{tabular}

${ }^{\mathrm{a}} R 1=\frac{\sum\|F o|-| F c\| \mid}{\sum|F o|} ;{ }^{\mathrm{b}} w R 2=\sqrt{\frac{\sum\left[W\left(F_{o}^{2}-F_{c}^{2}\right)\right]}{\sum\left[W\left(F_{o}^{2}\right)\right]}}$

and reduction. An absorption correction was applied. ${ }^{9}$ The structure was solved by the direct method using SHELXS-97 and was refined on $\mathrm{F}^{2}$ by full-matrix least-squares technique using the SHELXL-97 program package. ${ }^{10}$ Non-hydrogen atoms were refined anisotropically. In the refinement, hydrogens were treated as riding atoms using SHELXL default parameters. Crystal data and data collection parameters are given in table 1.

\section{Results and Discussion}

5,15-bisferrocenyl-10,20-bisphenylporphyrin, $\mathrm{H}_{2} \mathrm{Fc}_{2} \mathrm{Ph}_{2} \mathrm{P}$ prepared using the procedure reported previously. ${ }^{6 \mathrm{a}}$ Free ligand was refluxed with excess $\mathrm{FeCl}_{2}$ under $\mathrm{N}_{2}$ atmosphere which upon aerial oxidation and subsequent chromatographic purifications yields dark red 5,15-bisferrocenyl-10,20-bisphenyl chloro Fe(III) porphyrin, $\mathrm{Fe}^{\mathrm{III}}\left(\mathrm{Fc}_{2} \mathrm{Ph}_{2} \mathrm{P}\right) \mathrm{Cl}$. The UV-vis spectrum of $\mathrm{Fe}^{\mathrm{III}}\left(\mathrm{Fc}_{2} \mathrm{Ph}_{2} \mathrm{P}\right) \mathrm{Cl}$ in dichloromethane shows intense Soret band at $420 \mathrm{~nm}$ and two Q bands at 486 and $635 \mathrm{~nm}$. Upon addition of the acetonitrile solution of $\mathrm{AgClO}_{4}$ into the benzene solution of $\mathrm{Fe}^{\mathrm{III}}\left(\mathrm{Fc}_{2} \mathrm{Ph}_{2} \mathrm{P}\right) \mathrm{Cl}$, further change in the UV-vis spectra has been observed due to the formation of 5,15-bisferrocenyl10,20-bisphenyl perchlorato $\mathrm{Fe}(\mathrm{III})$ porphyrin, Fe $\mathrm{FIII}^{\mathrm{III}}$ $\left(\mathrm{Fc}_{2} \mathrm{Ph}_{2} \mathrm{P}\right) \mathrm{ClO}_{4}$ which was then isolated and spectroscopically characterized. UV-visible spectra of the complex show a Soret band at $397 \mathrm{~nm}$ with a Q band at $619 \mathrm{~nm}$. However, the addition of methanolic solution of $\mathrm{Cu}(\mathrm{OAC})_{2}$ into the $\mathrm{CHCl}_{3}$ solution of $\mathrm{H}_{2} \mathrm{Fc}_{2} \mathrm{Ph}_{2} \mathrm{P}$ and subsequent chromatographic purifications yields dark-red 5,15-bisferrocenyl-10,20-bisphenyl $\mathrm{Cu}$ (II) porphyrin, $\mathrm{Cu}^{\mathrm{II}}\left(\mathrm{Fc}_{2} \mathrm{Ph}_{2} \mathrm{P}\right)$ which was then isolated and structurally characterized. The UV-visible spectrum of the complex shows a Soret band at $415 \mathrm{~nm}$. Scheme 1 shows the synthetic outline of all the complexes reported here along with their abbreviations while figure 1 compares the UV-vis spectra of the representative complexes. However, detailed synthetic procedures

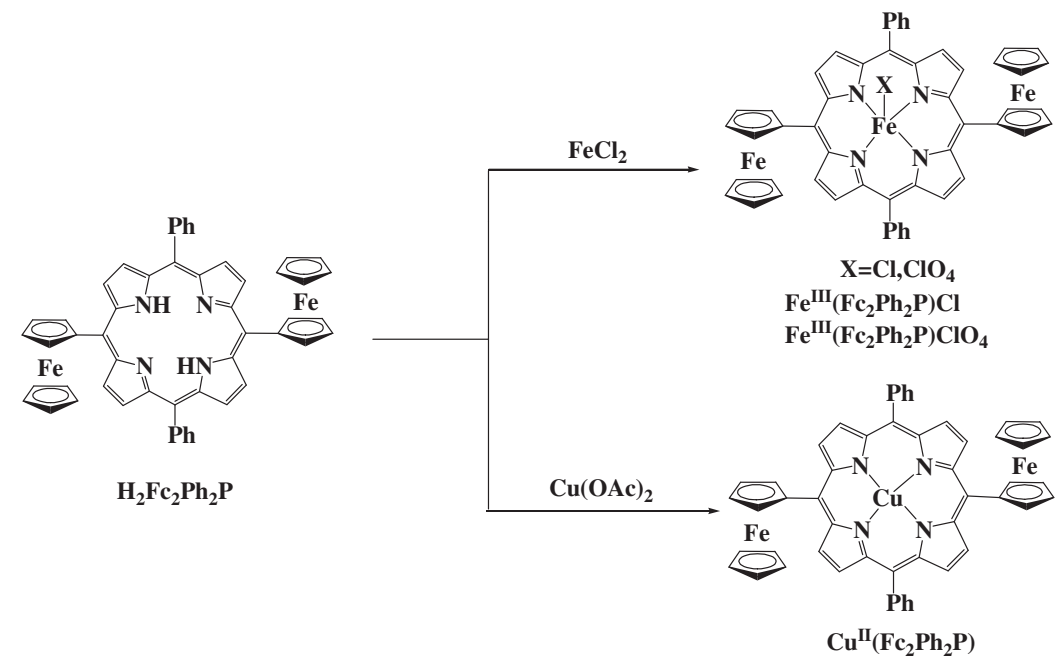

Scheme 1. List of complexes and their abbreviation. 


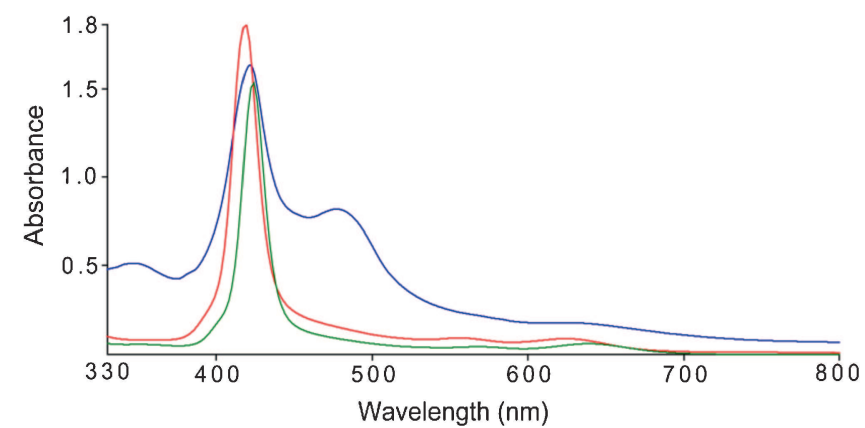

Figure 1. UV-visible spectra in dichloromethane of $\mathrm{H}_{2} \mathrm{Fc}_{2}$ $\mathrm{Ph}_{2} \mathrm{P}$ (green line), $\mathrm{Fe}^{\mathrm{III}}\left(\mathrm{Fc}_{2} \mathrm{Ph}_{2} \mathrm{P}\right) \mathrm{Cl}$ (blue line) and $\mathrm{Cu}^{\mathrm{II}}\left(\mathrm{Fc}_{2}\right.$ $\left.\mathrm{Ph}_{2} \mathrm{P}\right)$ (red line) at $295 \mathrm{~K}$.

along with the spectroscopic characterizations are given in the experimental section.

\subsection{Crystallographic characterization of $\mathrm{CuFc}_{2} \mathrm{Ph}_{2} \mathrm{P}$}

Dark-brown crystals of the molecule were obtained via slow diffusion of hexane into the chloroform solution of the molecule in air and one such crystals was chosen to mount on the Goniometer head for X-ray structure determination. The molecule crystallizes in the monoclinic crystal system with $P 2_{1} / \mathrm{c}$ space group, a perspective view is shown in figure 2 . In the asymmetric unit, 1/2 molecule of the complex is present and $\mathrm{Cu}$ metal ion is present at the centre of inversion. Crystal data and data collection parameters are listed in table 1 while the selected bond distances and angles

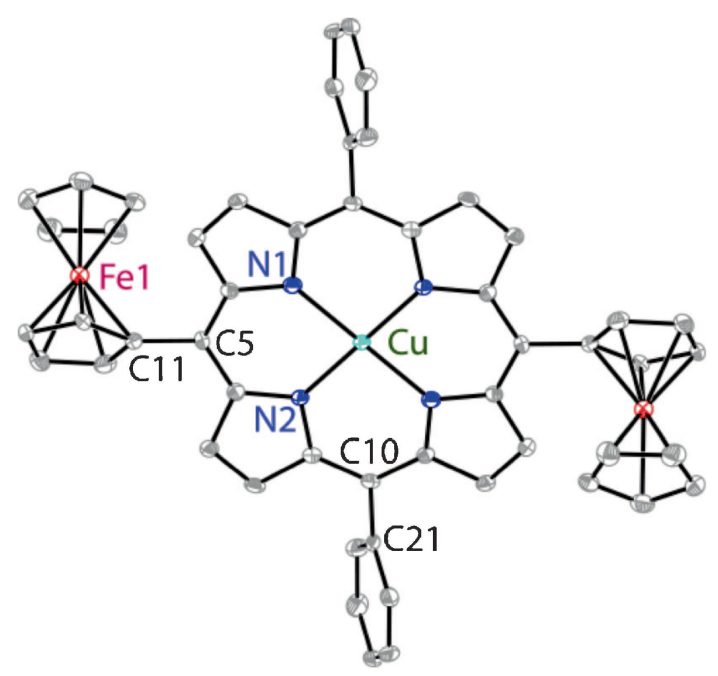

Figure 2. A perspective view of $\mathrm{Cu}^{\mathrm{II}}\left(\mathrm{Fc}_{2} \mathrm{Ph}_{2} \mathrm{P}\right)$ showing $50 \%$ thermal contours for all non-hydrogen atoms at $100 \mathrm{~K}$ (H- atoms have been omitted for clarity).
Table 2. Selected bond Lengths $(\AA)$ and angles (deg) for $\mathrm{Cu}^{\mathrm{II}}\left(\mathrm{Fc}_{2} \mathrm{Ph}_{2} \mathrm{P}\right)$.

\begin{tabular}{llll}
\hline $\mathrm{Cu}-\mathrm{N}(1)$ & $1.995(3)$ & $\mathrm{Fe}(1)-\mathrm{C}(17)$ & $2.044(5)$ \\
$\mathrm{Cu}-\mathrm{N}(2)$ & $2.013(3)$ & $\mathrm{Fe}(1)-\mathrm{C}(18)$ & $2.049(5)$ \\
$\mathrm{Fe}(1)-\mathrm{C}(11)$ & $2.073(4)$ & $\mathrm{Fe}(1)-\mathrm{C}(19)$ & $2.054(5)$ \\
$\mathrm{Fe}(1)-\mathrm{C}(12)$ & $2.069(4)$ & $\mathrm{Fe}(1)-\mathrm{C}(20)$ & $2.053(5)$ \\
$\mathrm{Fe}(1)-\mathrm{C}(13)$ & $2.052(4)$ & $\mathrm{C}(4)-\mathrm{C}(5)$ & $1.404(6)$ \\
$\mathrm{Fe}(1)-\mathrm{C}(14)$ & $2.040(5)$ & $\mathrm{C}(5)-\mathrm{C}(6)$ & $1.412(6)$ \\
$\mathrm{Fe}(1)-\mathrm{C}(15)$ & $2.008(4)$ & $\mathrm{C}(5)-\mathrm{C}(11)$ & $1.497(6)$ \\
$\mathrm{Fe}(1)-\mathrm{C}(16)$ & $2.030(5)$ & $\mathrm{C}(10)-\mathrm{C}(21)$ & $1.506(5)$ \\
$\mathrm{N}(1)-\mathrm{Cu}-\mathrm{N}(2)$ & $89.25(14)$ & $\mathrm{C}(6)-\mathrm{C}(5)-\mathrm{C}(11)$ & $120.9(4)$ \\
$\mathrm{C}(4)-\mathrm{C}(5)-\mathrm{C}(6)$ & $122.3(4)$ & $\mathrm{C}(9)-\mathrm{C}(10)-\mathrm{C}(1)$ & $123.9(4)$ \\
$\mathrm{C}(4)-\mathrm{C}(5)-\mathrm{C}(11)$ & $116.8(4)$ & $\mathrm{C}(1)-\mathrm{C}(10)-\mathrm{C}(21)$ & $117.3(4)$ \\
& & &
\end{tabular}

are given in table 2. The complex has a four coordinate square planar geometry in which the copper (II) atom is displaced by $0.03 \AA$ from the N4 plane of porphyrin. The average $\mathrm{Cu}-\mathrm{Np}$ distances is found to be $2.004(3) \AA$ which is similar to other four-coordinate $\mathrm{Cu}$ (II)porphyrins reported in the literature. ${ }^{11}$ It is, however, interesting to note that two ferrocene moieties are anti with respect to each other. The crystal packing shows the formation of well-separated stacks of molecules as illustrated in figure 3 .

The molecule $\mathrm{Cu}^{\mathrm{II}}\left(\mathrm{Fc}_{2} \mathrm{Ph}_{2} \mathrm{P}\right)$, shown in figure 2, has two ferrocenyl groups in the anti configuration. The porphyrin skeleton is essentially planar with only a slight distortion. Phenyl substituents were found to be nearly perpendicular $\left(75.3^{\circ}\right)$ to the porphyrin core while the $\mathrm{Cp}$ ring produces a torsion angle of $38^{\circ}$ with the porphyrin ring. The C5-C11 distance of 1.497(6) $\AA$ is similar with the C10-C21 distance of 1.506(5) $\AA$ implying almost no conjugation between the porphyrin ring and the ferrocenyl group. It is interesting to note that all the diferrocenyl porphyrins reported so far $^{6,7}$ aligned in a syn-orientation of two ferrocenyl groups while porphyrin rings are much more distorted compared to the same in $\mathrm{Cu}^{\mathrm{II}}\left(\mathrm{Fc}_{2} \mathrm{Ph}_{2} \mathrm{P}\right)$.

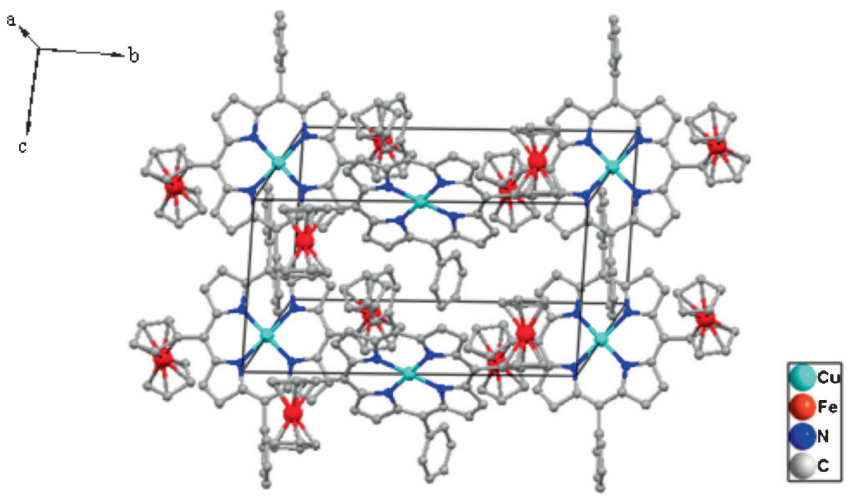

Figure 3. Diagram illustrating the packing of $\mathrm{Cu}^{\mathrm{II}}\left(\mathrm{Fc}_{2}\right.$ $\left.\mathrm{Ph}_{2} \mathrm{P}\right)$ in the unit cell. $\mathrm{H}$ - atoms have been omitted for clarity. 
The porphyrin macrocycle is distorted only slightly in the $\mathrm{Cu}^{\mathrm{II}}\left(\mathrm{Fc}_{2} \mathrm{Ph}_{2} \mathrm{P}\right)$ reported in the present work. This can be best appreciated by turning to figure 4 where the out-of-plane displacements in units of $0.01 \AA$ of the porphyrin core atoms are compared and, as can be seen, the porphyrin macrocycle is wave-distorted. It is, however, interesting to note that the porphyrin ring distortion is much less in $\mathrm{Cu}^{\mathrm{II}}\left(\mathrm{Fc}_{2} \mathrm{Ph}_{2} \mathrm{P}\right)$ when compared to the similar complexes reported in the literature.

\section{$3.2{ }^{1} H N M R$}

The structure and properties of the iron(III) porphyrins in solution can be obtained from their ${ }^{1} \mathrm{H}$ NMR spectra in $\mathrm{CDCl}_{3}$. The signals are broad and shifted to the downfield regions for the metal complexes compared to the free base porphyrin. The pyrrole- $H$ signals of $\mathrm{Fe}^{\mathrm{III}}\left(\mathrm{Fc}_{2} \mathrm{Ph}_{2} \mathrm{P}\right) \mathrm{Cl}$ and $\mathrm{Fe}^{\mathrm{III}}\left(\mathrm{Fc}_{2} \mathrm{Ph}_{2} \mathrm{P}\right) \mathrm{ClO}_{4}$ are observed at 78 and $36 \mathrm{ppm}$, respectively. The protons of the substituted $\mathrm{Cp}$ ring $(\alpha-\mathrm{Cp}, \beta-\mathrm{Cp})$ are observed as two non-equivalent sets while unsubstituted $\mathrm{Cp}$ ring $(\mathrm{CpH})$ shows only one signal, as expected. In $\mathrm{Fe}^{\mathrm{III}}\left(\mathrm{Fc}_{2} \mathrm{Ph}_{2} \mathrm{P}\right) \mathrm{Cl}$, the protons of the substituted $\mathrm{Cp}$ ring $(\alpha-\mathrm{Cp}, \beta-\mathrm{Cp})$ are downfield shifted to 12.2 and $13.2 \mathrm{ppm}$, respectively, compared to unsubstituted $\mathrm{Cp}$ ring $(\mathrm{CpH})$ which has been observed at $9.17 \mathrm{ppm}$. Also, protons from two phenyl substituents of the porphyrin core show a signal at $9.9 \mathrm{ppm}$. Similar spectral pattern have also been observed in $\mathrm{Fe}^{\mathrm{III}}\left(\mathrm{Fc}_{2} \mathrm{Ph}_{2} \mathrm{P}\right) \mathrm{ClO}_{4}$. Figure 5 compares the ${ }^{1} \mathrm{H} \mathrm{NMR}$ spectra in $\mathrm{CDCl}_{3}$ at $295 \mathrm{~K}$ for both the complexes.

NMR spectroscopy serves as a sensitive probe of spin state for paramagnetic heme complexes. ${ }^{12,13}$ Pyrrole$H$ signal of high-spin iron(III) meso-tetraarylporphyrin typically appear downfield at $\sim 80 \mathrm{ppm}$. As the iron moves towards the porphyrin mean plane in

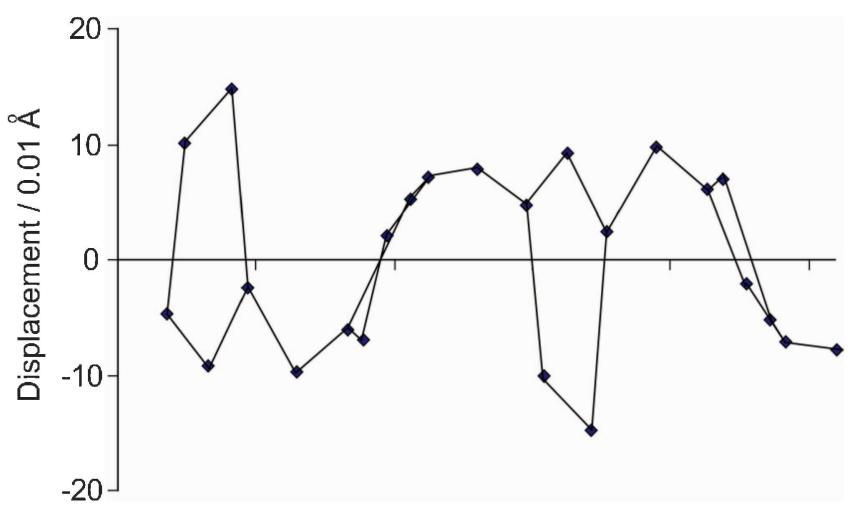

Figure 4. Out-of-plane displacements (in units of $0.01 \AA$ ) of the porphyrin core atoms of $\mathrm{Cu}^{\mathrm{II}}\left(\mathrm{Fc}_{2} \mathrm{Ph}_{2} \mathrm{P}\right)$ from the mean plane of the $\mathrm{C}_{20} \mathrm{~N}_{4}$ porphyrinato core. The horizontal axis shows the bond connectivity between atoms.

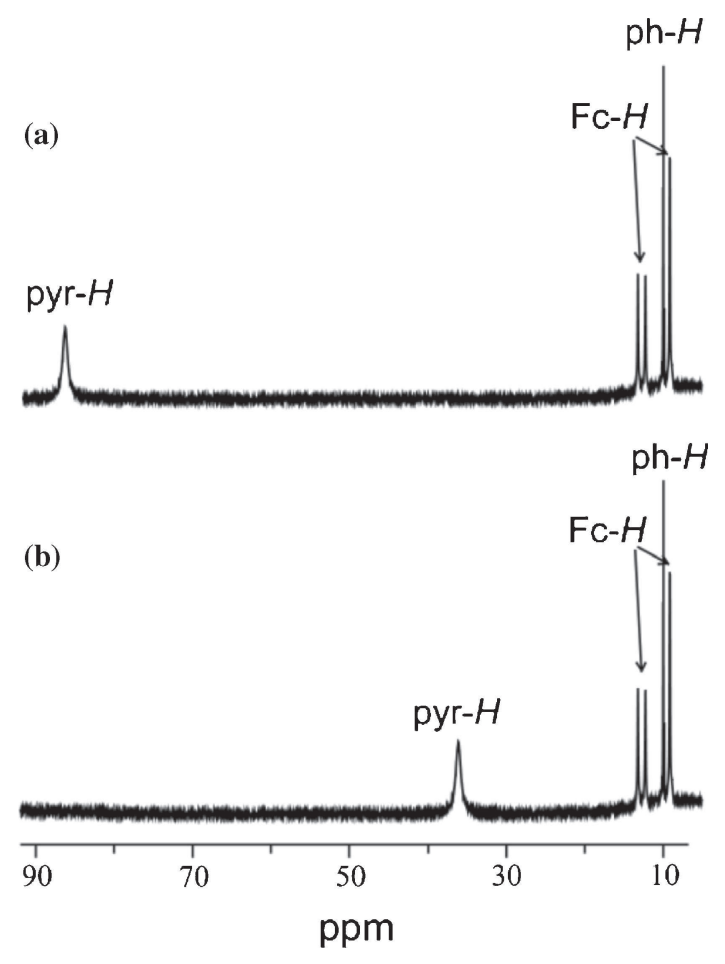

Figure 5. ${ }^{1} \mathrm{H}$ NMR spectra of (a) $\mathrm{Fe}^{\mathrm{III}}\left(\mathrm{Fc}_{2} \mathrm{Ph}_{2} \mathrm{P}\right) \mathrm{Cl}$ and (b) $\mathrm{Fe}^{\mathrm{III}}\left(\mathrm{Fc}_{2} \mathrm{Ph}_{2} \mathrm{P}\right) \mathrm{ClO}_{4}$ in $\mathrm{CDCl}_{3}$ at $295 \mathrm{~K}$.

spin-admixed complexes, pyrrole protons show upfield shift relative to those of the high-spin one. The differences in isotropic shifts between high-spin and spin-admixed complexes can be ascribed to decreased $\sigma$-contact shift contribution accompanying partial depopulation of the $\mathrm{d}_{(x 2-y 2)}$ iron orbital. ${ }^{12}$

Several factors control the spin states of iron(III) porphyrin complex. Among these, the number and nature of axial ligands are the most important factors. ${ }^{12,13}$ While most of the anionic ligands such as halides and hydroxide lead to the formation of the complexes with high-spin $(\mathrm{S}=5 / 2)$ state, extremely weak ligands such as $\mathrm{ClO}_{4}^{-}$give invariably the admixed $(\mathrm{S}=3 / 2,5 / 2)$ spin state, as also observed here.

\section{$3.3 \quad E P R$}

The EPR spectral measurements are carried out at 120 $\mathrm{K}$ in solution. The spectra are axially symmetric with $\mathrm{g}_{\perp}=5.95$ and $\mathrm{g}_{\mathrm{II}}=1.99$ for $\mathrm{Fe}^{\mathrm{III}}\left(\mathrm{Fc}_{2} \mathrm{Ph}_{2} \mathrm{P}\right) \mathrm{Cl}$ and $\mathrm{g}_{\perp}=5.68$ and $\mathrm{g}_{\mathrm{II}}=2.00$ for $\mathrm{Fe}^{\mathrm{III}}\left(\mathrm{Fc}_{2} \mathrm{Ph}_{2} \mathrm{P}\right) \mathrm{ClO}_{4}$ in dichloromethane. The representative spectra are shown in figure 6. These results are suggestive of high-spin $\mathrm{Fe}(\mathrm{III})(\mathrm{S}=5 / 2)$ nature of $\mathrm{Fe}^{\mathrm{III}}\left(\mathrm{Fc}_{2} \mathrm{Ph}_{2} \mathrm{P}\right) \mathrm{Cl}$ and admixed spin state of iron in $\mathrm{Fe}^{\mathrm{III}}\left(\mathrm{Fc}_{2} \mathrm{Ph}_{2} \mathrm{P}\right) \mathrm{ClO}_{4}$ in solution.

Figure 7 shows the spectrum obtained from $\mathrm{Cu}^{\mathrm{II}}\left(\mathrm{Fc}_{2}\right.$ $\mathrm{Ph}_{2} \mathrm{P}$ ) in dichloromethane at $120 \mathrm{~K}$. The spectra are axially symmetric with $\mathrm{g}_{\perp}=2.06$ and $\mathrm{g}_{\mathrm{II}}=2.21$ for $\mathrm{Cu}^{\mathrm{II}}$ $\left(\mathrm{Fc}_{2} \mathrm{Ph}_{2} \mathrm{P}\right)$ in dichloromethane indicating of low-spin 

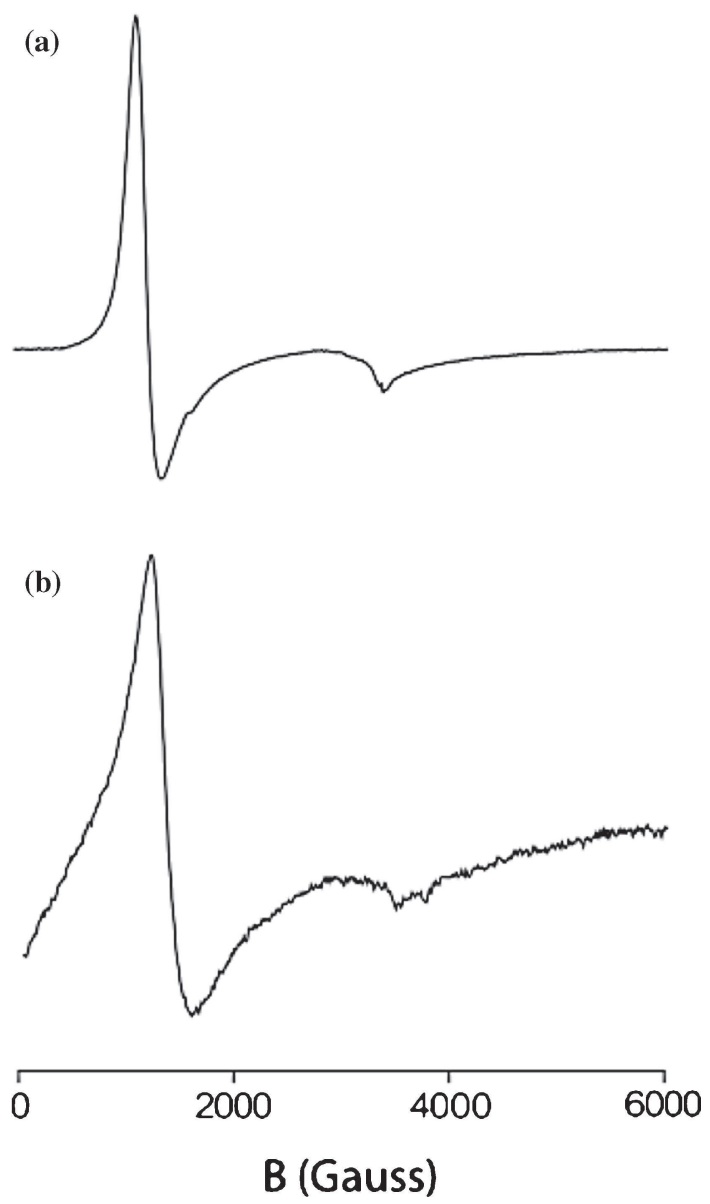

Figure 6. $\mathrm{X}$-band EPR spectra of (a) $\mathrm{Fe}^{\mathrm{III}}\left(\mathrm{Fc}_{2} \mathrm{Ph}_{2} \mathrm{P}\right) \mathrm{Cl}$ and (b) $\mathrm{Fe}^{\mathrm{III}}\left(\mathrm{Fc}_{2} \mathrm{Ph}_{2} \mathrm{P}\right) \mathrm{ClO}_{4}$ in $\mathrm{CH}_{2} \mathrm{Cl}_{2}$ at $120 \mathrm{~K}$.

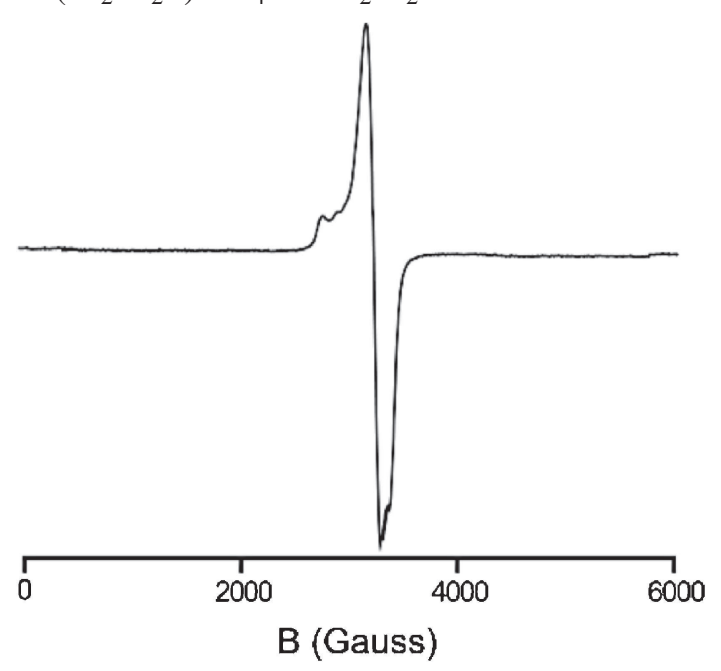

Figure 7. $\mathrm{X}$-band EPR spectra of complex $\mathrm{Cu}^{\mathrm{II}}\left(\mathrm{Fc}_{2} \mathrm{Ph}_{2} \mathrm{P}\right)$ in $\mathrm{CH}_{2} \mathrm{Cl}_{2}$ at $120 \mathrm{~K}$.

( $\mathrm{S}=1 / 2)$ state of $\mathrm{Cu}$ (II) which is similar with other $\mathrm{Cu}^{\mathrm{II}}$-porphyrins known in the literature. ${ }^{14}$

\subsection{Electrochemistry}

Electrochemistry provides some information on the $\pi$-conjugated porphyrin systems. Cyclic voltammetry were performed at $295 \mathrm{~K}$ under $\mathrm{N}_{2}$ in $\mathrm{CH}_{2} \mathrm{Cl}_{2}$ using $0.1 \mathrm{M}$ tetrabutylammonium hexa-fluorophoshate (TBAH) as the supporting electrolyte. It has been found that within the solvent electrochemical window, all observed redox processes in the target porphyrins exhibited quasi-reversible behaviour. Also, ferrocenebased oxidation was observed between porphyrincentered oxidation and reduction waves in all the cases.

Electrochemical properties of $\mathrm{H}_{2} \mathrm{Fc}_{2} \mathrm{Ph}_{2} \mathrm{P}$ and its metal complexes $\mathrm{Fe}^{\mathrm{III}}\left(\mathrm{Fc}_{2} \mathrm{Ph}_{2} \mathrm{P}\right) \mathrm{Cl}$ and $\mathrm{Cu}^{\mathrm{II}}\left(\mathrm{Fc}_{2} \mathrm{Ph}_{2} \mathrm{P}\right)$ in dichloromethane have been thoroughly investigated. Figure 8 displays the cyclic voltammetry of the complexes while their redox potentials are given
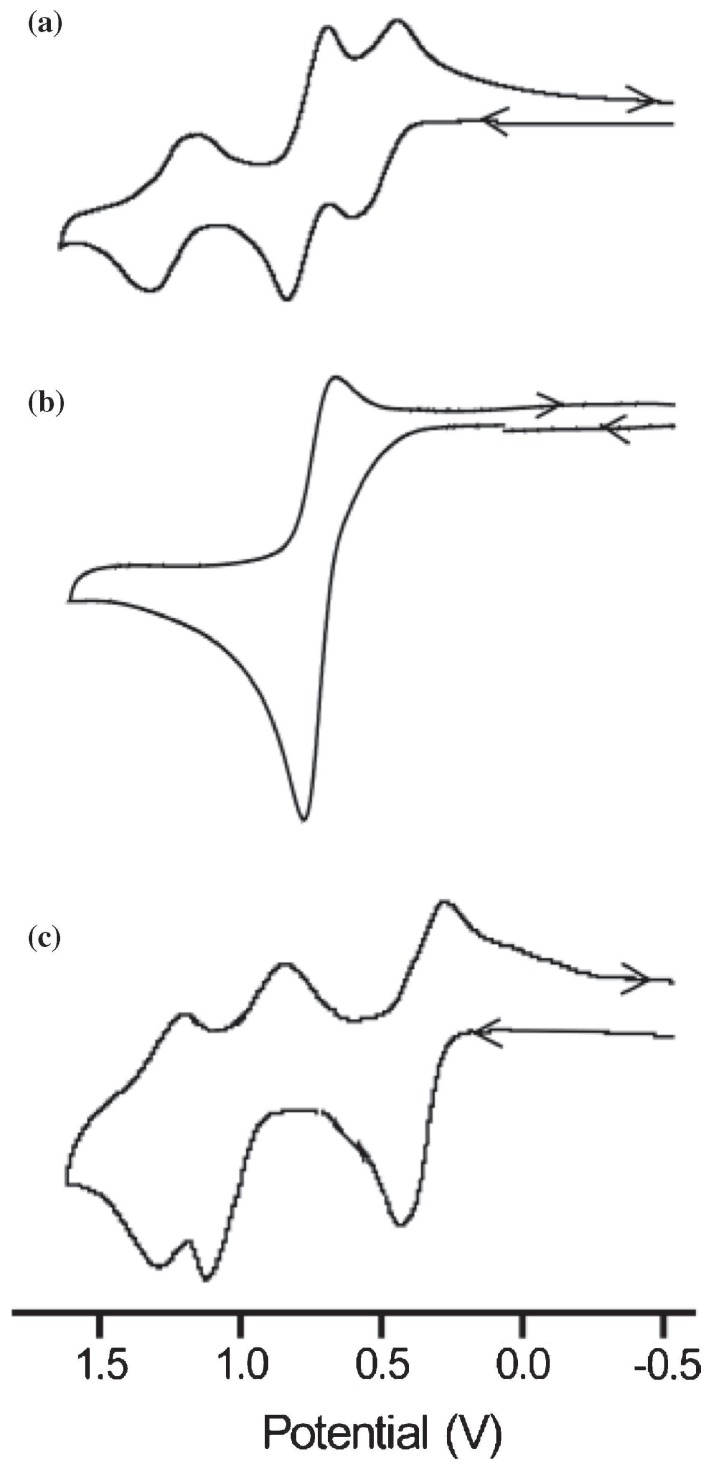

Figure 8. Cyclic voltammogram (selected portions) of (a) $\mathrm{H}_{2} \mathrm{Fc}_{2} \mathrm{Ph}_{2} \mathrm{P}$, (b) $\mathrm{Fe}^{\mathrm{III}}\left(\mathrm{Fc}_{2} \mathrm{Ph}_{2} \mathrm{P}\right) \mathrm{Cl}$ and (c) $\mathrm{Cu}^{\mathrm{II}}\left(\mathrm{Fc}_{2} \mathrm{Ph}_{2} \mathrm{P}\right)$ in $\mathrm{CH}_{2} \mathrm{Cl}_{2}$ (scan rate $100 \mathrm{mV} / \mathrm{s}$ ) with 0.1 tetrabutylammonium hexa-fluorophoshate (TBAH) as supporting electrolyte at $295 \mathrm{~K}$. The reference electrode was $\mathrm{Ag} / \mathrm{AgCl}$. 
in the experimental section. The ferrocenyl groups of $\mathrm{H}_{2} \mathrm{Fc}_{2} \mathrm{Ph}_{2} \mathrm{P}$ undergo two quasi-reversible one-electron transfer processes at 0.51 and $0.74 \mathrm{~V}$, respectively. The values of half-wave oxidation potentials indicate that the ferrocenyl groups in the compounds are slightly more difficult to oxidize than that of free ferrocene. The separation of the two ferrocene oxidation waves in $\mathrm{H}_{2} \mathrm{Fc}_{2} \mathrm{Ph}_{2} \mathrm{P}$ indicative of strong coupling of the ferrocene moieties. However, metallation of the diferrocenyl porphyrins also affects the oxidation potential of ferrocenyl groups. Cyclic voltammetry of $\mathrm{Cu}^{\mathrm{II}}\left(\mathrm{Fc}_{2} \mathrm{Ph}_{2} \mathrm{P}\right)$ displays a single two-electron oxidative response at $0.44 \mathrm{~V}$ related to the oxidation of two ferrocene moieties which is further confirmed using spectro-electrochemistry (vide infra). The relatively easier ferrocenyl oxidation might be considered as a consequence of the great electron releasing ability of the porphyrin ring upon metallation with $\mathrm{Cu}(\mathrm{II})$. Similar to $\mathrm{Cu}^{\mathrm{II}}\left(\mathrm{Fc}_{2} \mathrm{Ph}_{2} \mathrm{P}\right)$, the cyclic voltammetry of $\mathrm{Fe}^{\mathrm{III}}\left(\mathrm{Fc}_{2} \mathrm{Ph}_{2} \mathrm{P}\right) \mathrm{Cl}$ also displays a single quasireversible two-electron oxidations at $0.72 \mathrm{~V}$ which indicates that two ferrocenyl groups are electrochemically separated. Here the higher oxidation state of $\mathrm{Fe}(\mathrm{III})$ is observed to reduce the electron releasing tendency of the porphyrin ring and thus make the ferrocene oxidation difficult. The porphyrin core, however, lacks substituents at the $\beta$-pyrrolic positions, and the ferrocenyl moieties are therefore free to rotate. It would be interesting to note that cyclic voltammetric response of 5,15-diferrocenyl-2,8,12,18tetraethyl-3,7,13,17-tetramethylporphyrin $\left(\mathrm{H}_{2} \mathrm{DFTTP}\right)$ and its metal complex M(DFTTP) [M: $\mathrm{Mn}$ (III)Cl, Ni(II) and $\mathrm{Zn}(\mathrm{II})]$ displayed two 1e-oxidative response of the ferrocene moieties indicative of strong metal-metal coupling between two ferrocene; however, the ferrocene moieties have been observed to be syn with respect to each other while porphyrin ring was highly deformed. ${ }^{6,7}$

\subsection{Spectro-electrochemistry}

Spectroelectrochemical studies are very much informative about the coupling between ferrocene units and have been used to obtain spectroscopic signatures of oxidized species originating from the neutral compounds. The ferrocenyl groups of trans $-\mathrm{H}_{2} \mathrm{Fc}_{2} \mathrm{Ph}_{2} \mathrm{P}$ displays two one-electron oxidation process at 0.51 and $0.74 \mathrm{~V}$, respectively. The successive removal of individual electrons from the ferrocene substituents, however, confirms the long-distance metal-metal coupling in the trans $-\mathrm{H}_{2} \mathrm{Fc}_{2} \mathrm{Ph}_{2} \mathrm{P}$, which was further supported by the spectroelectrochemical and chemical oxidation experiments. ${ }^{6 \mathrm{a}}$ The formation of the mixed-valence trans- $\left[\mathrm{H}_{2} \mathrm{Fc}_{2} \mathrm{Ph}_{2} \mathrm{P}\right]^{+}$species was accompanied by a redshift in the Soret band from 424 to $448 \mathrm{~nm}$, a loss of Q-band intensity at $623 \mathrm{~nm}$ and $697 \mathrm{~nm}$, the appearance of the $650 \mathrm{~nm}$ band, and a characteristic IVCT band observed at $854 \mathrm{~nm}$ which supports the elimination of an electron from the ferrocene moiety. ${ }^{6 a}$ The second one-electron oxidation of trans- $\left[\mathrm{H}_{2} \mathrm{Fc}_{2} \mathrm{Ph}_{2} \mathrm{P}\right]^{+}$, however, resulted in the disappearance of the IVCT band, along with the appearance of a band at $708 \mathrm{~nm}$, and the shift of the Soret band to $470 \mathrm{~nm}^{6 \mathrm{a}}$

Bulk coulometric oxidations of $\mathrm{Fe}^{\mathrm{III}}\left(\mathrm{Fc}_{2} \mathrm{Ph}_{2} \mathrm{P}\right) \mathrm{Cl}$ and $\mathrm{Cu}^{\mathrm{II}}\left(\mathrm{Fc}_{2} \mathrm{Ph}_{2} \mathrm{P}\right)$ were performed in dichloromethane at applied potentials of 0.65 and $0.92 \mathrm{~V}$ for two electron oxidations of each complex, respectively, using $0.1 \mathrm{M}$ TBAH as supporting electrolyte under nitrogen and the progress of the reactions are monitored by UV-visible spectroscopy which are shown in figure 9. Similar observations have also been obtained during the chemical oxidation. During 2e-oxidations of $\mathrm{Cu}^{\mathrm{II}}\left(\mathrm{Fc}_{2} \mathrm{Ph}_{2} \mathrm{P}\right)$ (figure $9 \mathrm{~A}$ ), the Soret band at $415 \mathrm{~nm}$ and a Q-band at $652 \mathrm{~nm}$ decreases in intensity and revealed a new band at $555 \mathrm{~nm}$, characteristic of the charge-transfer band observed in ferrocenium cations. No intervalence charge transfer (IVCT) band, indicative of mixed-valence compounds are observed during
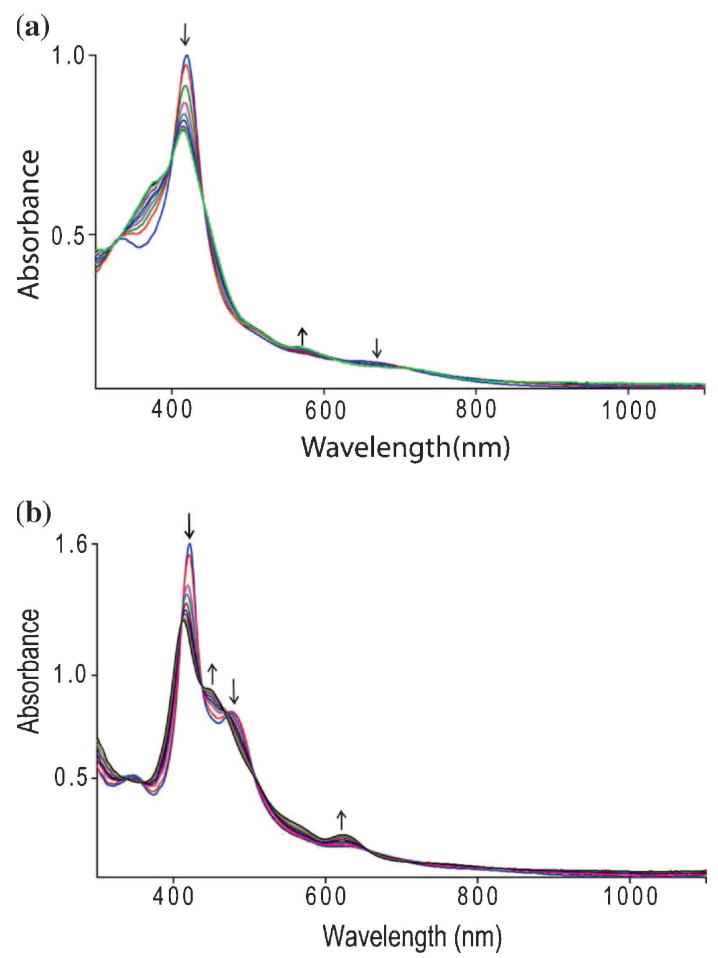

Figure 9. UV-visible spectral change (in dichloromethane) upon 2e-oxidation of (a) $\mathrm{Cu}^{\mathrm{II}}\left(\mathrm{Fc}_{2} \mathrm{Ph}_{2} \mathrm{P}\right)$ and (b) $\mathrm{Fe}^{\mathrm{II}}\left(\mathrm{Fc}_{2}\right.$ $\left.\mathrm{Ph}_{2} \mathrm{P}\right) \mathrm{Cl}$ at $295 \mathrm{~K}$; arrows indicate increase or decrease of band intensity. 
the oxidation process. Similarly, for $\mathrm{Fe}^{\mathrm{III}}\left(\mathrm{Fc}_{2} \mathrm{Ph}_{2} \mathrm{P}\right) \mathrm{Cl}$, the Soret band has blue-shifted from 421 to $414 \mathrm{~nm}$ with a loss in intensity. Two new Q-bands at 454 and $635 \mathrm{~nm}$ have also appeared during the oxidation process (figure 9b).

Step-wise oxidations of $\mathrm{Fe}^{\mathrm{III}}\left(\mathrm{Fc}_{2} \mathrm{Ph}_{2} \mathrm{P}\right) \mathrm{Cl}$ and $\mathrm{Cu}^{\mathrm{II}}$ $\left(\mathrm{Fc}_{2} \mathrm{Ph}_{2} \mathrm{P}\right)$ were also performed using silver triflate (AgOTf) as chemical oxidants under nitrogen and have been monitored using UV-visible spectroscopy. However, the observations are very similar with the results obtained in spectrochemical studies shown above. The present study suggests that two ferrocenyl moieties are electrochemically separated in the $\mathrm{Fe}$ (III) and $\mathrm{Cu}$ (II) complexes and thus demonstrates the importance of metal ion on the long-range electronic communication for such types of complexes.

\section{Conclusions}

$\mathrm{Fe}^{\mathrm{III}}\left(\mathrm{Fc}_{2} \mathrm{Ph}_{2} \mathrm{P}\right) \mathrm{Cl}, \mathrm{Fe}^{\mathrm{III}}\left(\mathrm{Fc}_{2} \mathrm{Ph}_{2} \mathrm{P}\right) \mathrm{ClO}_{4}$ and $\mathrm{Cu}^{\mathrm{II}}\left(\mathrm{Fc}_{2} \mathrm{Ph}_{2} \mathrm{P}\right)$ have been synthesized and characterized by UV-vis, ${ }^{1} \mathrm{H}$ NMR, EPR and single crystal $\mathrm{X}$-ray diffraction study for $\mathrm{Cu}^{\mathrm{II}}\left(\mathrm{Fc}_{2} \mathrm{Ph}_{2} \mathrm{P}\right)$. X-ray structure of $\mathrm{Cu}^{\mathrm{II}}\left(\mathrm{Fc}_{2} \mathrm{Ph}_{2} \mathrm{P}\right)$ shows two ferrocene moieties in anti conformation with respect to each other for the first time, which is in contrast to all other diferrocenyl porphyrin where the ferrocenyl unit is syn. Phenyl substituents were found to be nearly perpendicular $\left(75.3^{\circ}\right)$ to the porphyrin core while the $\mathrm{Cp}$ ring produces a torsion angle of $38^{\circ}$ with the porphyrin plane of the molecule. It is, however, interesting to note that the porphyrin ring distortion is much less (wave-distorted) in $\mathrm{Cu}^{\mathrm{II}}\left(\mathrm{Fc}_{2} \mathrm{Ph}_{2} \mathrm{P}\right)$ when compared to the similar complexes reported in the literature. EPR and ${ }^{1} \mathrm{H}$ NMR studies confirm the highspin and admixed-spin of iron in $\mathrm{Fe}^{\mathrm{III}}\left(\mathrm{Fc}_{2} \mathrm{Ph}_{2} \mathrm{P}\right) \mathrm{Cl}$ and $\mathrm{Fe}^{\mathrm{III}}\left(\mathrm{Fc}_{2} \mathrm{Ph}_{2} \mathrm{P}\right) \mathrm{ClO}_{4}$, respectively.

The ferrocenyl groups of $\mathrm{H}_{2} \mathrm{Fc}_{2} \mathrm{Ph}_{2} \mathrm{P}$ undergo two quasi-reversible one-electron transfer processes at 0.51 and $0.74 \mathrm{~V}$, respectively. However, the ferrocenyl groups of $\mathrm{Cu}^{\mathrm{II}}\left(\mathrm{Fc}_{2} \mathrm{Ph}_{2} \mathrm{P}\right)$ are more easily oxidized via a single two-electron quasi-reversible process (at $0.44 \mathrm{~V}$ ) than ferrocene. The easier ferrocenyl oxidation might be considered as a consequence of the great electron releasing ability of the porphyrin ring. Also, the ferrocene subunits of $\mathrm{Fe}^{\mathrm{III}}\left(\mathrm{Fc}_{2} \mathrm{Ph}_{2} \mathrm{P}\right) \mathrm{Cl}$ are oxidized by a single two-electron transfer process at $0.72 \mathrm{~V}$, indicating that two ferrocenyl groups are electrochemically separated. The higher oxidation state of Fe(III) reduces the electron releasing tendency of the porphyrin ring and thus make the ferrocene oxidation difficult. Spectro-electrochemical study thus revealed ferrocenebased two-electron quasi-reversible oxidation of the complexes reported here with no observable coupling of the ferrocene moieties. The porphyrin, however, lacks substituents at the $\beta$-pyrrolic positions, and the ferrocenyl moieties are therefore free to rotate. The observed electrochemical analyses thus demonstrate that the oxidation of the ferrocene subunit is strongly affected by porphyrin ring as well as the central metal through extended $\pi$-conjugation.

\section{Supplementary Information}

CCDC-976062 contain the X-ray crystallographic details in $\mathrm{CIF}$ format for $\mathrm{Cu}^{\mathrm{II}}\left(\mathrm{Fc}_{2} \mathrm{Ph}_{2} \mathrm{P}\right)$. The data can be obtained free of charge at www.ccdc.cam.ac.uk/ conts/retrieving.html or [from the Cambridge Crystallographic Data Center, 12 Union Road, Cambridge CB2 1EZ, UK; Fax: +44 1223336 033; E-mail: deposit@ccdc.cam.ac.uk].

\section{Acknowledgement}

We thank the Department of Science and Technology, Government of India and the Council of Scientific and Industrial Research (CSIR), New Delhi for financial support. DS thanks CSIR, India for his fellowship.

\section{References}

1. (a) Miller J S and Epstein A J 1984 Angew. Chem. Int. Ed. 33 385; (b) Epstein A J and Miller J S 1996 Synth. Met. 80 231; (c) Barlow S and O'Hare D 1997 Chem. Rev. 97 637; (d) Kaim W and Lahiri G K 2007 Angew. Chem. Int. Ed. 46 1778; (e) Kaim W and Sarkar B 2007 Coord. Chem. Rev. 251 584; (f) Chisholm M H and Patmore N J 2007 Acc. Chem. Res. 40 19; (g) Solomon E I, Sarangi R, Woertink J S, Augustine A J, Yoon J and Ghosh S 2007 Acc. Chem. Res. 40581

2. (a) Wasielewski M R 1992 Chem. Rev. 92 435; (b) Gust D, Moore T A, Moore A L 1993 Acc. Chem. Res. 26 198; (c) Health J R, Kuekes P J, Snider G S and Williams R S 1998 Science 280 1716; (d) Chen Y, Jung J, Ohlberg D, Li X, Stewart D R, Jeppesen K A, Stoddart J F and Williams R S 2003 Nanotechnol. 14 462; (e) Beer P D, Gale P A, Chen G Z, 1999 Coord. Chem. Rev. 185-186 3; (f) Bard A J 1995 Nature 374 13; (g) Matsushige K, Yamada H, Tada H, Horiuchi T and Chen X Q 1998 Ann. N. Y. Acad. Sci. 852 290; (h) Liu Z, Yasseri A A, Lindsey J S and Bocian D F 2003 Sci. 3021543

3. (a) Grimm B, Hausmann A, Kahnt A, Seitz W, Spanig F and Guldi D M In Handbook of Poprhyrin Science; Kadish K K, Smith K M and Guilard R 2010 Eds.; World Scientific: Singapore, 1 133; (b) Suijkerbuijk B M J M and Gebbink R J M K 2008 Angew. Chem. Int. Ed. 47 7396

4. Bucher C, Devillers C H, Moutet J C, Royal G, SaintAman E 2009 Coord. Chem. Rev. 25321 
5. (a) Nemykin V N, Rohde G T, Barrett C D, Hadt R G, Sabin J R, Reina G, Galloni P, and Floris B 2010 Inorg. Chem. 49 7497; (b) Boyd P D W, Burrell A K, Campbell W M, Cocks P A, Gordon K C, Jameson G B, Officer D L and Zao Z 1999 Chem. Commun. 637; (c) Rhee S W, Na Y H, Do T and Kim J 2000 Inorg. Chim. Acta 30949

6. (a) Nemykin V N, Rohde G T, Barrett C D, Hadt R G, Bizzarri C, Galloni P, Floris B, Nowik I, Herber R H, Marrani A G, Zanoni R and Loim N M 2009 J. Am. Chem. Soc. 131 14969; (b) Nemykin V N, Galloni P, Floris B, Barrett C D, Hadt R G, Subbotin R I, Marrani A G, Zanoni R and Loim N M 2008 Dalton Trans 4233; (c) Nemykin V N, Barrett C D, Hadt R G, Subbotin R I, Maximov A Y, Polshin E V and Koposov A Y 2007 Dalton Trans. 3378; (d) Rochford J, Rooney A D and Pryce M T 2007 Inorg. Chem. 46 7247; (e) Kim J, Rhee S W, Na Y H, Lee K P, Do Y and Jeoung S C 2001 Bull. Korean Chem. Soc. 22 1316; (f) Rhee S W, Park B B, Do Y and Kim J 2000 Polyhedron 191961

7. Li Q, Mathur G, Gowda S, Surthi S, Zhao Q, Yu L, Lindsey J S, Bocian D F and Misra V 2004 Adv. Mater. 16133

8. SAINT+ 19996.02 (ed) Bruker AXS, Madison, WI

9. Sheldrick G M 2000 SADABS 2.0

10. Sheldrick G M 1997 SHELXL-97: Program for Crystal Structure Refinement; University of Göttingen: Göttingen, Germany

11. (a) Sinelshchikova A A, Nefedov S E, Enakieva Y Y, Gorbunova Y G, Tsivadze A Y, Kadish K M, Ping C, Bessmertnykh Lemeune A, Stern C and Guilard R 2013 Inorg. Chem. 52 999; (b) Harmjanz M and Scott M J
2000 Inorg. Chem. 39 5428; (c) Birnbaum E R, Hodge J A, Grinstaff M W, Schaefer W P, Henling L, Labinger J A, Bercaw J E and Gray H B 1995 Inorg. Chem 34 3625; (d) Chen W, El-Khouly M E and Fukuzumi S 2011 Inorg. Chem. 50 671; (e) Chen W and Fukuzumi S 2009 Eur. J. Inorg. Chem. 5494

12. Weiss R, Gold A and Terner J 2006 Chem. Rev. 1062550

13. (a) Bhowmik S, Dey S, Sahoo D and Rath S P 2013 Chem. Eur. J. 19 13732; (b) Bhowmik S, Ghosh S K, Layek S, Verma H C and Rath S P 2012 Chem. Eur. J. 18 13025; (c) Bhowmik S, Sil D, Patra R and Rath S P 2011 J. Chem. Sci. 123 827; (d) Bhowmik S, Ghosh S K and Rath S P 2011 Chem. Commun. 47 4790; (e) Ghosh S K, Patra R and Rath S P 2010 Inorg. Chem. 49 3449; (f) Ghosh S K and Rath S P 2010 J. Am. Chem. Soc. 132 17983; (g) Chaudhary A, Patra R and Rath S P 2010 Eur. J. Inorg. Chem. 5211; (h) Sahoo D, Quesne M G, de Visser S P and Rath S P 2015 Angew. Chem. Int. Ed. 54 DOI: 10.1002/anie.201411399; (i) Sainna M A, Sil D, Sahoo D, Martin B, Rath S P, Comba P and de Visser S P 2015 Inorg. Chem. 54 1919; (j) Sil D, Khan F S T and Rath S P 2014 Inorg. Chem. 53 11295

14. (a) Konarev D V, Neretin I S, Slovokhotov Y L, Yudanova E I, Drichko N V, Shulga Y M, Tarasov B P, Gumanov L L, Batsanov A S, Howard J A K, and Lyubovskaya R N 2001 Chem. Eur. J. 12 2605; (b) Cunningham K L, McNett K M, Pierce R A, Davis K A, Harris H H, Falck D M and McMillin D R 1997 Inorg. Chem 36 608; (c) Kivelson D and Robert N 1961 J.Chem.Phys. 35149 